\title{
DISCURSOS EMOLDURADOS: APONTAMENTOS PARA A HISTÓRIA DO MUSEU DE ARTE DE SANTA CATARINA
}

\author{
Lucésia Pereira' \\ Universidade Federal de Santa Catarina
}

RESUMO:

O estudo histórico do antigo Museu de Arte Moderna de Florianópolis (MAMF), atual Museu de Arte de Santa Catarina (MASC), apresenta muitas questões em aberto, merecendo um olhar mais atento da historiografia no sentido de avançar sobre uma série de noções cristalizadas sobre seu papel na cultura institucionalizada. O contato com a produção de memórias, discursos, sua política arquivística e suas relações com a cidade constituem o leque de interesses deste artigo.

\section{PALAVRAS-CHAVE:}

Museu. Cultura. Imagem. Discurso. Arte Moderna

\begin{abstract}
:
The study of the history of the Museum of Modern Art in Florianópolis (MAMF), current Art Museum of Santa Catarina (MASC), presents many open questions, deserving a closer look in its historiography, in a sense to move forward on a number of crystallized notions about its role in an institutionalized culture. The contact with the production of memoirs, speeches, policy and archival imagery with the power of its collection are the range of interests of this research.
\end{abstract}

\section{KEY-WORDS:}

Museum. Culture. Image. Discours. Modern Art.

I O título do artigo se refere a Tese de Dourado, defendida em 2013 no Programa de Pós-Graduação em História da Universidade Federal de Santa Catarina, a partir de recursos concedidos pelo Cnpq. 
Parcela da bibliografia disponível sobre o antigo Museu de Arte Moderna Florianópolis (MAMF) ${ }^{2}$, apresenta uma série de discursos cristalizados da sua história e consequentemente do seu papel na cultura institucionalizada.A perpetuação de tais discursos se dá a partir de uma visão neutra do arquivo. Ela desconsidera que em todas as instâncias de um museu, inclusive do seu arquivo, estão presentes relações de poder. Do ponto de vista de sua materialidade, é preciso considerar a presença de uma questão ética e política na escolha do indício que ficou retido, do mesmo modo sobre o que será encoberto e esquecido, "pois o arquivo, assim como o processo de musealização, é uma construção voluntária de caráter seletivo e político, vinculado a um esquema de atribuição de valores: culturais, ideológicos, religiosos, econômicos, etc." (CHAGAS, 2002, p. 60).

A principal referência que embasa tais discursos foi produzida no próprio museu na década de 1980, quando este estava sob a direção de Harry Laus (1922-1992). Escritor e crítico de arte, Laus foi um dos diretores mais atuantes do MASC, tendo por duas vezes dirigido a instituição. Em meados dos anos oitenta, quando assumiu pela primeira vez este cargo, trazia entre outras experiências o desempenho jornalístico na crítica de arte do eixo Rio/São Paulo e de ter estado à frente do Museu de Arte de Joinville (1980/1982). Além das ideias para exposições (realizadas ou não), que merecem por si só um estudo específico pela criatividade e ineditismo, ele desenvolveu soluções museológicas interessantes no sentido de organizar e dinamizar as duas instituições desta natureza que estiveram sob seu comando.Ao contrário de alguns dos diretores que lhe antecederam no posto, Harry Laus não pertencia apenas aos meios políticos e artísticos da capital e talvez por isso tenha dedicado esforços para abrir o MASC para a produção de várias regiões. Direto em suas afirmações, ele criticou abertamente - através dos documentos e textos que publicou em jornais e revistas de alcance local e nacional - o mau uso do dinheiro público em aquisições questionáveis para o acervo, denunciou o desaparecimento de obras importantes e se mostrou descontente com as nomeações feitas pelo governo estadual na área da cultura. Sua equipe fez frente a diversas áreas da atividade museal, a começar pelo levantamento documental do que havia sido retido ao longo do tempo. Esta ação, em particular, era condizente com aspectos da sua conduta pessoal, pois durante sua vida Harry Laus foi um sujeito voltado tanto para a geração de registros quanto para a sua organização ${ }^{3}$. A considerar este fato, é compreensível a crítica do escritor às condições da documentação encontradas no museu que, segundo declarou na época, se constituía em um amontoado de papéis, aparentemente preservados de modo aleatório e assistemático. Convencido da ineficiência dos processos de arquivamento do MASC, Laus (1987) revelou que "[...] seu arquivo era incompleto e confuso, praticamente impossibilitando o acesso a informações precisas sobre suas origens e sobre os dilemas de habitação e direção".

No espírito de colocar a "casa em ordem", a equipe que atuava junto com Harry Laus fez frente à questão arquivística do MASC, tanto no sentido de um levantamento e ordenação dos documentos, quanto a posterior escritura acerca do que foi encontrado. ${ }^{4}$ Este movimento antecedeu as comemorações dos

20 MAMF foi oficializado por um decreto em 1949, quando eram decorridos seis meses de uma exposição de arte trazida pelo escritor e marchand carioca Marques Rebelo (1907/1973) para Florianópolis. Desde 1969 a instituição passou a ser conhecida como Museu de Arte de Santa Catarina (MASC). Com base nesta mudança, as referências ao museu serão feitas da seguinte maneira: até 1969 utilizaremos a sigla MAMF e, a partir daí MASC.

$3 \bigcirc$ arquivo deixado por Harry Laus está depositado no Núcleo de Pesquisa de Literatura e Memória (NULIME), do Curso de Pós-Graduação em Literatura da Universidade Federal de Santa Catarina.

4 Em parte, o mérito desta realização é atribuído a Terezinha Sueli Franz, funcionária da Fundação Catari- 
38 anos do museu e resultou na montagem de quatro exposições simultâneas para comemorar o acontecimento. Uma dessas exposições chamada Memória Gráfica apresentava em painéis, ordenados temporalmente, o resultado do trabalho de seleção e classificação da documentação separada e organizada na ocasião, colocando o percurso do MAMF/MASC numa perspectiva de historicidade,

A 'memória do Masc' é um levantamento da memória do museu e compõe cultura, e uma exposição de painéis com fotografias, recortes de jornais, catálogos e cartazes que permitirá uma revisão gráfica de toda a história do museu no período de 1949 a 1987 (MASC ABRE..., 1987, p. 16).

A versão construída na oportunidade teve ecos duradouros e se tornou essencial nos discursos posteriores. Daí pra frente, diversas publicações reeditam esta proposta histórica, muitas vezes destacando os mesmos acontecimentos e personagens. Entre tais publicações estão as que são feitas pelo museu, inclusive seu principal catálogo impresso em 2002, chamado Biografia de um museu (BORTOLIN, 2002). Apesar do tempo decorrido, entre sua publicação e Memória Gráfica (por volta de 20 anos), muitos textos foram ali republicados tal qual haviam sido produzidos na época de Harry Laus.

Desta maneira, a equipe que realizou as atividades em prol da história e memória do MASC nos anos oitenta, além de ter salvado os documentos então existentes de uma maior dispersão, instaurou também um regime de verdade que ainda preside parte do que é dito sobre o museu. Entre os problemas em tornar fundante esta ou qualquer outra proposta de uma história derradeira, é que ela não contabiliza fatores como os apagamentos sobre vários processos da instituição como, por exemplo, das políticas de aquisição e de tombamento de obras. Neste sentido, a preocupação aqui registrada não desconsidera a relevância do trabalho realizado na época, no enfrentamento da questão histórica, mas alerta para a necessidade de que outros decalques sejam propostos ao que já é discutido, de acordo com as demandas do presente. Faz-se necessário uma revisão destes discursos, conforme propõe Michel Foucault em Arqueologia do Saber (FOUCAULT, 20I2) ao escrever que é vital para a ciência histórica se libertar das noções de continuidade e repetição.

A partir do olhar crítico vemos que muitos eventos que impactaram o MAMF/MASC são tratados nestes discursos sob uma perspectiva de neutralidade. Entre eles consta a mudança de terminologia em 1969 e a transferência para o Centro Integrado de Cultura (CIC) em 1979.Além disso, há questões invisíveis como o fato do museu ter sido palco de jogos políticos de afirmação de identidades, contrariando o fundamento de que eles devem existir para o benefício e o adiantamento do povo (conforme era o pensamento dos anos cinquenta). A história da relação do Museu com a cidade carece também de abordagens atualizadas que problematizem o seu papel institucional ajustado as políticas culturais do governo do estado. É preciso reconhecer os investimentos simbólicos que os agentes políticos lançaram sobre a cultura, fazendo com que o espaço se convertesse numa arena onde colocaram em afirmação os seus interesses.

Um museu como resposta

Assinalou Oliveira (2008), que o aparecimento do Museu em Florianópolis foi entendido tanto no contexto dos anos de 1950 quanto nos discursos poste-

nense de Cultura (FCC).A FCC foi criada em 1979, com vistas ao gerenciamento das instituições culturais de SC. 
riores, como um grande passo, uma linha divisória de um novo tempo para uma região que tinha sobre si mesma uma percepção de atraso, de ser provinciana em relação às outras capitais. De fato, se for para se recorrer aos números, na maior parte dos estudos - sejam demográficos, econômicos ou culturais - se observa que, quando comparados a outras capitais, inclusive a vizinha Porto Alegre, os de Florianópolis são modestos, a começar pelos seus 69.122 habitantes nos anos de $1950^{5}$. É por esta época que os olhares técnicos apontam a baixa produtividade do seu porto, principal esteio da economia urbana, baseada no comércio de mercadorias ${ }^{6}$. Com a atividade portuária em extinção e sem uma base industrial que permitisse alavancar a economia, cujos indíces eram crescentemente desfavoráveis, frente aos mostrados por outras cidades catarinenses - algumas sendo redutos da colonização alemã e italiana -, a capital precisava responder à situação e garantir a sua prevalência. $O$ turismo (indústria sem chaminés), voltado para a apreciação dos atrativos naturais junto à invenção de uma tradição cultural relacionada ao modo de vida dos imigrantes vindos dos Açores, foi uma das ações deflagradas em Florianópolis, a partir dos anos de 1950 no sentido de superar esta condição.

Foi no início desta década que o museu conquistou sua primeira sede, sendo alojado num imóvel situado numa das principais ruas do centro da capital. $\bigcirc$ espaço que chegou a funcionar nos moldes de um centro cultural era denominado de Casa de Santa Catarina. Em seus metros quadrados estavam reunidos, num clima de objetivos comuns, o Instituto Histórico e Geográfico de Santa Catarina (IHGSC) ${ }^{7}$, instituição ligada ao século XIX, a recém-criada Comissão Catarinense do Folclore (CCF) e o jovem museu destinado a exibir a arte contemporânea. Há, porém, vestígios documentais que mostram que antes de ser constituída a Casa de Santa Catarina, o espaço havia sediado uma associação recreativa mantida pela comunidade alemã, conhecida como Clube Germânia. No contexto nebuloso gerado pela Segunda Guerra o imóvel foi desapropriado pelo governo do estado.

Sobre ambos os espaços (Clube Germânia e depois Casa de Santa Catarina) a documentação residual é escassa. Sem uma pesquisa específica, há limites ao que pode ser dito sobre os objetivos de sua criação e o papel que estas instituições tiveram no contexto estético/político daqueles anos e seus conflitos. O fato é que no período estava colocada uma complicada questão identitária, envolvendo os diferentes grupos étnicos de Santa Catarina. Da parte do governo, era manifesto o repúdio que sustentava com relação ao modo de vida das comunidades imigrantes (principalmente de alemães e italianos) que, segundo o discurso oficial das autoridades, se caracterizava pela manutenção dos antigos costumes pátrios. No caso alemão, a intenção última desta continuidade nos costumes seria fundar um apêndice da Alemanha na região sul da América - a fábula da Alemanha Antarctica. A falta de base comprobatória para tal proposição não impediu que a situação fosse declaradamente encarada como uma ameaça ao processo de nacionalização do país. Lembremos que ele tinha como principal mandamento a necessidade da unificação cultural e linguística.

Mas, conforme o cenário antes esboçado, vimos que o que estava em jogo, ultrapassava a pretensão de uma identidade cultural dos catarinenses des-identificada do conflito internacional, mas a própria preponderância política e cultural da capital de Santa Catarina em face da prosperidade econômica observada nas regiões de colonização, principalmente do norte do estado. Diante da aliança

5 Conforme dados do censo demográfico do Estado de Santa Catarina, 1950. Fonte: Peluso Junior (1975). 6 Para saber mais sobre este contexto, consultar Sant'anna (2005).

7 O IHGSC foi criado em 07/09/1896. 
feita entre Brasil e Estados Unidos e a constante ameaça a sua hegemonia, as elites políticas de Florianópolis investiram na realização do I Congresso de História Catarinense, acontecido em 1948, portanto, no mesmo ano da exposição organizada por Marques Rebelo ${ }^{8}$, evento considerado a gênese do MAMF. Este foi o momento de alavancar um projeto que estes grupos alimentavam há certo tempo, pois a invenção de discursos evocativos da herança luso-brasileira já vinha se constituindo desde o inicio do século através das publicações do IHGSC. O congresso foi um evento marcante para fixar um estereótipo para o ser catarinense, que pelo investimento feito sobre uma suposta origem, passou, a partir daí, a ser identificado menos com a do imigrante empreendedor e mais com açoriano habitante do litoral e seu modo de vida.

Independente de qualquer espectro obsedante do passado, a constituição da Casa de Santa Catarina mostrou a intenção das elites locais em formar no local um centro cultural, gerador de ideias. $O$ acontecido revelava ainda as manipulações políticas presentes nesses processos de construção de identidades e invenção de tradições. Em face da consolidação do discurso vencedor e temporário (a considerar os câmbios futuros), é inquestionável que a transformação do clube Germânia nesse espaço simbolizava uma demonstração de força dos grupos dirigentes da capital, servindo para amainar o caráter temerário de sua posição no estado. A Casa de Santa Catarina contribuiria para dar legitimidade ao saber-poder que emanava da parceria entre o estado e os sujeitos que se ocupavam em pensar as diretrizes culturais para suas instituições.

Vimos dessa forma, que o MAMF/MASC foi parte constituinte dos jogos identitários, justamente no contexto afirmativo dos emblemas regionais da capital. Mais tarde, a crescente mercantilização da cultura foi impondo outras matrizes a estes discursos, porém, manteve-se o silêncio que encobriu como um verniz a história de barbárie relacionada a tais processos. Os ressentimentos gerados, por sua vez, foram mantidos numa antecâmara da história, mas eles regressariam incessantemente e demandariam dos governos seguintes constantes rearranjos entre política e memória.

\section{Extremidades}

Por um decreto estadual publicado em junho de 1970, o Museu de Arte Moderna de Florianópolis passou a ser denominado Museu de Arte de Santa Catarina. Na maior parte dos discursos sobre este câmbio, o acontecimento aparece como algo irrelevante, um evento casual e sem maiores implicações políticas ou ideológicas. Neste espírito, o catálogo Biografia de um Museu apenas menciona em suas páginas a nova terminologia assumida pelo espaço. Mas, isto é apenas um modo de ver a questão.

Em 20II, Lima apresentou a situação sob um novo enfoque e avançou sobre a visão superficial defendendo que a mudança foi parte da negociação e trânsito entre as noções de arte moderna e contemporânea que correspondiam também aos fluxos mais gerais do pensamento cultural do período. Em sua ótica, para que tal modificação acontecesse, foram fundamentais as deliberações acontecidas no I Colóquio de Museologia" onde "[...] a maioria considerou que devem ser adotados nomes genéricos e não restritivos. Exemplo: Museu de Arte de Santa Catarina e não Museu de Arte Moderna de Florianópolis. Seria assim evitada a delimitação no campo de ações da entidade" (LAUS, 1966).

8 A respeito do congresso, ver Sayão (2004).

9 I Colóquio dos Diretores de Museus de Arte, realizado no Museu de Arte Contemporânea da USP em São Paulo, entre 27 e 28 setembro de 1966. 
É mesmo provável que a exclusão da arte moderna da terminologia do museu significasse um passo no sentido de posicionar a instituição junto a um pensamento museológico de diretrizes mais atuais e "universais". Mas, é preciso incorporar a esta percepção que a alteração atendia também a questões internas do sistema artístico e político do estado, pois, além de um novo pensamento museológico, surgiram novas linguagens, espacialidades e diferentes relações entre política, cultura e mercado.

Um dos elementos a ser incorporado na abordagem da mudança é relativo ao mapa da produção cultural, já que as regiões apartadas da capital vinham conquistando cada vez mais autonomia. Em distintas medidas, passou a existir em outras cidades um sistema de artes envolvendo o jornalismo crítico, as exposições, a atuação dos artistas e o próprio mercado, havendo uma importante movimentação, especialmente entre cidades como Lages, Joinville e Blumenau e os outros dois estados do sul do Brasil. Estas iniciativas foram muito diversificadas e organizadas individualmente pelos artistas ou em grupos de afinidade.A questão é que longe do eixo costumeiro (do qual o MASC fazia parte) os artistas construíram meios próprios de ganhar visibilidade e criar espaços que acolhessem obras, debates e ideias, como a galeria Açu-Açu, fundada em Blumenau, em 1970, e considerada uma das mais importantes galerias particulares do estado.

Com o objetivo de fomentar um mercado turístico, o discurso de promoção do estado, buscou incorporar os atrativos culturais das principais regiões além do já consagrado litoral. $\mathrm{Na}$ época, a ideia de uma única matriz cultural - a açoriana (fortalecida no congresso de açorianeidade de 1948) - foi cedendo lugar a outra que procurava mostrar Santa Catarina como um mosaico de culturas que povoavam em harmonia os seus territórios,

Santa Catarina não é somente a faixa litorânea, nem principalmente a capital. O Estado é composto, bem sabemos, das mais variadas regiões geográficas nas quais estabeleceram-se considerável quantidade de imigrantes gaúchos, alemães, italianos, portugueses, russos, holandeses e poloneses além de outros formando uma colcha de retalhos culturais estendida sobre uma superfície completamente acidentada e variada. São alemães na planície, no vale e no planalto; italianos em regiões montanhosas e no litoral, por exemplo, colorindo espetacularmente o solo cultural catarinense. Sendo assim, constituindo cada região um núcleo cultural riquíssimo em tradições e em potencialidade criativa, cada uma delas tem suas manifestações próprias, trazidas ou adquiridas no próprio habitat, bem diversa das demais, suas vizinhas catarinenses, mas ao mesmo tempo, impossibilitando a própria integração cultural de Santa Catarina (MAIS UM..., I97I).

Com os interesses voltados em mostrar as essências regionais, a mudança de nome era estrategicamente importante para o governo do estado, pois promovia um sentido de que o museu pertencia a todos os catarinenses. Desta maneira, não obstante a aparência de neutralidade, além da mudança no pensamento museal e da dinamização cultural das regiões catarinenses, a nova terminologia aconteceu também por influência direta das políticas identitárias e sua crescente mercantilização.

\section{Paredes do tempo}

É preciso salientar que se hoje é possível conceber a ideia de um museu que existe apenas no nosso imaginário, graças às inúmeras possiblidades abertas 
pelos mecanismos de reprodutibilidade de imagens, a noção ainda encontraria pouco sentido nos anos cinquenta quando as instituições museais eram pensadas a partir de um lugar-espaço reservado para a exposição, culto e guarda do acervo. A falta de um domicílio adequado para efetivar estas ações, foi um dos permanentes percalços enfrentados pelo museu nas três primeiras décadas de funcionamento. Inicialmente, o problema foi contornado pela promessa (irrealizada) da construção de um complexo moderno para abrigá-lo. Porém, a despeito das boas intenções o MAMF/MASC esteve sujeito a uma existência nômade, até que foi transferido em 1982 para o conjunto arquitetônico do Centro Integrado de Cultura $(\mathrm{CIC})$ onde está até hoje.

Antes dessa “derradeira" mudança, o MASC esteve instalado (desde 1979) no casarão onde funcionou a alfândega que atendia a extinta cidade portuária. Construído em 1875, o amplo edifício em estilo neoclássico fica na parte mais central de Florianópolis, precisamente no limite entre a cidade e o mar, conforme o traçado original da Vila de Nossa Senhora do Desterro. Fechado quando o porto foi desativado em 1964, o prédio foi tombado como monumento nacional e restaurado pelo governo federal que o cedeu sem ônus ao estado em $1977^{10}$. A rua onde está a velha Alfândega, a Conselheiro Mafra, é uma das mais movimentadas vias comerciais da cidade e está próxima dos terminais de ônibus, da principal praça, do velho mercado.A antiga Rua do Príncipe sofreu intervenções importantes, tendo parte do seu casario tombado pelo município. A remodelação, que aconteceu por volta da época em que o museu foi lá alojado, deu prosseguimento à restrição da atividade de prostituição ali existente. Levando em conta o investimento feito sobre a região como lugar de memória e o fato de estar no caminho de um grande fluxo de pessoas, é mesmo possível que, nos três anos passados ali, o museu estivesse mais integrado à vida urbana, conforme comentaram funcionários do MASC.A comparação foi feita em relação ao conjunto arquitetônico do Centro Integrado de Cultura (CIC).

Nas modernas características deste complexo, finalmente o museu alcançava a modernidade arquitetônica já pretendida desde os anos cinquenta. Como um marco positivo, a transferência dotou a instituição de um ambiente amplo e novo, dispondo o museu de uma área de $1.980 \mathrm{~m}^{2}$.A exaltação com as novas instalações transparece numa matéria escrita pelo ex-diretor Harry Laus e publicada na revista Tempos Modernos, em 1985. Com regozijo, ele, que na época estava na direção do MAMF, ponderava sobre a nova condição alcançada no moderno complexo do $\mathrm{CIC}$. $\mathrm{O}$ aspecto das novas instalações, descrito pelo crítico de arte, parecia estar mais condizente com as mudanças ocorridas no interior da própria instituição que, no fluxo mais geral dos processos artísticos, se abria para a arte contemporânea e poderia assim atender a sua demanda expositiva.

Contudo, o transplante do museu para o $\mathrm{CIC}$ não contou apenas com aspectos positivos. Dez anos depois da mudança, Harry Laus lamentava que o acervo do museu encontrava-se numa condição vexatória para a cultura catarinense devido às condições inadequadas de guarda e às limitações enfrentadas na exposição do acervo, condenado à invisibilidade.

E onde está tudo isto que o povo não vê? Escondido numa sala do $\mathrm{CIC}$, sofrendo em silêncio o desprezo de governos que se sucedem, sem a sensibilidade e a compreensão daquele período. Esta célula dos tempos dourados, mantida intacta por mais de quarenta anos, apesar de todos

I0 As características estéticas da construção e seu papel na história da cidade foram elementos determinantes para encaixá-lo dentro da política de preservação do SPHAN que, desde os anos cinquenta, estava focada na herança colonial e barroca. 
os contratempos, vem sendo acrescida de novos valores da arte brasileira e hoje são mais de novecentos prisioneiros da ingraditão. Por ironia, essa prisão fica no lado oposto da rua que abriga a penitenciária, na Agronômica, sem que esses degredados tenham sequer o direito humanitário de um passeio ao sol [...] (LAUS, 1996, p. 172).

Sob a ótica da democratização do espaço, é preciso pelo menos considerar o fator antes mencionado sobre a pouca integração do museu com a vida urbana. $\mathrm{O} \mathrm{CIC} \mathrm{foi} \mathrm{erguido} \mathrm{numa} \mathrm{área} \mathrm{situada} \mathrm{entre} \mathrm{a} \mathrm{penitenciária} \mathrm{da} \mathrm{Pedra}$ Grande e a Avenida Beira Mar Norte que, já nos anos oitenta, atendia a um grande fluxo de veículos. ". Se levarmos em conta o acesso como um dos fatores de democratização dos lugares públicos, no $\mathrm{ClC}$, a visitação restringiu o tipo de expectador do MASC. Talvez os registros dos índices de visitação (os quais não pesquisamos) confirmassem se de fato o afastamento do burburinho citadino foi problemático no ponto de vista da visitação do museu, conforme sugerem os depoimentos antes mencionados.

Se por um lado a urbanização daquela região traduzia a expansão da cidade com suas novas geografias, ela instituía novas formas de passagem, distintas do sentido de flânerie ${ }^{12}$ celebrado por Baudelaire. A cidade que ia se conformando trazia práticas sociais distintas e até paradoxais, porque eram contrárias às experiências vividas nas estruturas socioespaciais anteriores com seus sedimentos.

\section{Permanências}

Em 201I o MASC foi reaberto depois de estar fechado por 2 anos para uma prolongada e polêmica reforma. ${ }^{13}$ Para a ocasião foi realizada uma dupla exposição: Tempo, espaço e arte e Linhas artísticas. A primeira apresentava a história do museu desde a sua criação até a definitiva instalação no $\mathrm{CIC}$. Do ponto de vista de seu conteúdo, tanto os painéis afixados no salão de exposição quanto o texto que compõe o (muito bem ilustrado) catálogo do evento, praticamente, não trazem nada de novo, uma vez que foram parcialmente reeditadas as já conhecidas histórias sobre a fundação, sobre a relação deste acontecimento com o grupo modernista, sobre a suposta incompreensão local da arte moderna, entre outras. Em geral, são os mesmos discursos dos nos anos oitenta, cujos limites já mencionamos. Como é usual, as autoridades públicas destacaram nesta reabertura a importância do MASC, reafirmando algumas expectativas com relação ao espaço.A este respeito, se pronunciou um representante oficial, com a seguinte declaração:

Com esse evento de memória simbolizada, o Governo do estado, por meio da Fundação Catarinense de Cultura, entrega o MASC dinamizado e equipado, com inovações que o colocam definitivamente no circuito nacional, no padrão de outros equipamentos brasileiros do gênero, e que, por certo, levara á ampliação das possiblidades de construção de identidades e a percepção crítica acerca das realidades artisticas e culturais (MUSEU DE ARTE DE SANTA CATARINA, 20I I).

I I Como acontece ainda hoje, o local não tem uma linha regular de ônibus que, de fato, deixe os frequentadores em suas portas.

I2 A flânerie, prática social moderna, diz respeito ao descompromissado e deliberado vagar pela cidade.

13 A promessa inicial era reabrir o espaço em 240 dias, todavia o espaço continuou fechado muito mais tempo do que o noticiado (fechado em 05/2009, reabriu em 06/20I I). 
Sobre à possibilidade de construção de identidades destacada na mensagem, sabemos que no passado isto aconteceu muito mais pelas interferências do governo do que pelas apropriações simbólicas que a população projetou no museu. $\mathrm{Na}$ atualidade, isto se torna um objetivo polêmico e duvidoso, pois a cidade mudou consideravelmente e, apesar de toda nostalgia sentida pelos antigos moradores, ela mantém apenas um pálido reflexo da urbe de 1950. Hoje, a área metropolitana de Florianópolis possui por volta de um milhão de pessoas e tem enfrentado os problemas estruturais desta expansão, inclusive a carência de espaços culturais. Além disso, afirma Meneses (1993), as noções de identidades culturais são problemáticas, entre outras razões, por pressuporem uma lógica de pertencimento e, como tal, estabecerem diferenças que fundam defesas e privilégios. Transformada em palavra de ordem no museu, cabe-lhe o desafio de produzir discursos, ou seja, lugares de identificação que, alheios às históricas exclusões, contemplem a diversidade, atendendo a demanda plena da sociedade e não apenas de determinados grupos. Em síntese, a questão é: Como fazer com que os significados, a serem construídos em tal processo, expressem um futuro de democracia cultural ao mesmo tempo em que não maquiem a desigualdade do presente?

\section{Referência}

BORTOLIN, Nancy (Org.). Catálogo biografia de um museu. Florianópolis: FCC, 2002. CHAGAS, Mário. Há uma gota de sangue em cada museu: a ótica museológica de Mario de Andrade. Chapecó:Argos, 2006.

FOUCAULT, Michel.Arqueologia do saber. Rio de Janeiro: Forense Universitária, 2012. LAUS, Harry. Crítica aos órgãos da cultura. Jornal do Brasil, Rio de Janeiro, fev. 1966. Arquivo MASC.

LAUS, Harry. Discurso de abertura do catálogo. 1987. Texto datilografado.

LAUS, Ruth. Harry Laus: artes plásticas. Rio de Janeiro: Cervantes, 1996.

LIMA, Sueli. Arquivo, museu, contemporâneo: a fabricação do conceito de arte contemporânea no Museu de Arte de Santa Catarina - MASC/SC. 201I. Tese (Doutorado)- Universidade Federal de Goiás, Faculdade de História, $201 \mathrm{I}$.

MAIS UM veículo de integração cultual no Estado. Revista Catarinense, Florianópolis, n. 20, 1971. Arquivo Biblioteca Pública do Estado de Santa Catarina.

MALRAUX,André. O museu imaginário. Lisboa: Edições 70, 2000.

MASC ABRE 3 exposições e revive sua história. Jornal A Notícia, Florianópolis, p. 16, 12 mar. 1987. Arquivo MASC.

MENESES, Ulpiano T. Bezerra de.A problemática da identidade cultural nos museus: de objetivo (de ação) a objeto do conhecimento. Anais do Museu Paulista Nova Série, n. I, 1993. Disponível em: <http://www.scielo.br/pdf/anaismp/vIn l/ a $14 \mathrm{v} \mid \mathrm{nl}$.pdf>. Acesso em: 10 maio 2012.

MUSEU DE ARTE DE SANTA CATARINA. Catálogo da exposição: tempo, espaço e arte e Linhas Artísticas. [S.I.: s.n.], 20I I.

OLIVEIRA, Emerson Dionísio. Um acervo de arte moderna e contemporânea e a identidade institucional. Revista História em Reflexão, v. 2, n. 4, jul./dez. 2008. Disponível em: <www.historiaemreflexao.ufgd.edu.br>.Acesso em: 10 fev. 2012. PELUSO JUNIOR, Victor Antonio. A evolução urbana de Santa Catarina no período de 1940 a 1970. Revista do Instituto Histórico e Geográfico de Santa Catarina, v. 3, n. I, 1975. 
SANT'ANNA, Mara Rúbia. Poder e aparência: novas sociabilidades urbanas em Florianópolis de 1950 a 1970.2005. Tese (Doutorado em História)- Instituto de Filosofia, Letras e Ciências Humanas, Universidade Federal do Rio Grande do Sul, Porto Alegre, 2005.

SAYÃO, Thiago Juliano. Nas veredas do folclore: leituras sobre política cultural e identidade em Santa Catarina (1948-1975). 2004. Dissertação (Mestrado em História)- Centro de Filosofia e Ciências Humanas, UFSC, Florianópolis, 2004.

ZILIO, Carlos.A questão política no modernismo. In: FABRIS, Annateresa (Org.). Modernidade e modernismo no Brasil. Porto Alegre: Zouck, 2010.

Artigo recebido em junho de 2013. Aprovado em agosto de 2013 